\title{
Organization of Intelligent Memory Introducing Cluster Access
}

\author{
Simon Berkovich* \\ Department of Computer Science, The George Washington University, USA
}

Submission: April 01, 2017; Published: April 13, 2017

"Corresponding author: Simon Berkovich, Department of Computer Science, The George Washington University, Washington, USA, Email: berkov@gwu.edu

\section{Introduction}

This note presents a novel concept of organization of memory for intelligent operations. and Theoretical Biology. Straightforwardly, entry to memory is performed by sequential, cyclic or random access depending on the physical configuration of the information storage. A more sophisticated contentaddressable access is produced by an elaborate design of associative memory. Evidently, content-addressability offers essential processing advantages over direct physical access. However, a higher goal of extracting sense from associative memory stumbles upon an intricate problem of resolution of multiple responses.

The traditional methods of resolution of multiple responses have very limited rational utility. The most effectual resolution of the problem of multiple responses was achieved by Google's Page rank that purportedly presents the answers in order of their potential suitability to customers' objectives. However, a truly intelligent system must offer something beyond of what it has been asked - to give a meaningful outlook of the situation based on the obtainable contents of the memory. In other words, an intelligent memory has to produce its own rational reaction in the sense not exactly awaited by the user. To this end we suggest a new operational access to large memories based on selection of clusters of data items including the given requested data item. We will consider how this operation can be organized for Big Data systems [1,2] and for the human brain [3]. Before we would like strongly emphasize that the suggested method of cluster access is different from may look similar: fuzzy access to associative memory. This later access provides vague neighborhoods to the content of a requested data item, while the cluster access incorporates the explored data item in a proper cluster. This concept, "Making sense of Big Data' is going to be presented on Track 2 (Bio-IT World Conference \& Expo 2017 Boston, MA http://www.giiconference.com/chi369052/datacomputing.shtml) by our graduate student Chen Shen.

In contrast to traditional information systems aimed at concrete data retrievals, Big Data systems are striving for a delicate product of knowledge. So, Big Data processing is similar to investigations by Scientific Method, namely, this processing has to make hypothetical predictions subject to practical verifications. Such Computations entail manipulations with clusters rather than with individual objects. We have developed an efficient technique for cluster access using the error correction ideas from communications. Exclusively, one of the existing error correction codes-Golay code is "perfect" in the sense that its 23-bit vectors for transmission are covering the whole range of possible $2^{23}$ outputs. Thus, the usage of Golay code can be reversed from communications to information retrieval with 23bit templates. As a result we get a very fast procedures for fuzzy searching, $\mathrm{O}(1)$, and clustering, $\mathrm{O}(\mathrm{N})$ [1]. Big Data systems can benefit from the developed methodology, as long as information items are mapped into 23-bit templates. Information systems, for Precision Medicine, can get such templates naturally by building Boolean expressions from biomarkers.

As described in [3], similar processing scheme develops for the operations of the brain following the cloud computing paradigm suggested in [4]. Performance of human memory is the most perplexing phenomenon of Nature. The renowned physicist S. Weinberg wrote: "How memories are stored in the brain is not likely to be affected by the discovery of the final theory" So, physics that cannot explain the operability of the brain is not just incomplete; it is incorrect. Putting the brain in the cornerstone of the quest for understanding Nature gives us a methodological advantage as long as the a priori principles for information processing are more certain than the intuitive conjectures of Natural Philosophy. The computational model for Big Data explicitly operates merely on a restricted part of data, but the whole data contents enables data extraction implicitly. Thus, brain actively utilizes about a tiny one gigabit of information on top of a very huge unconsciousness.

The key problem is how such computational efforts are organized. Any computational process is a combination of two basic elementary activities: memory write-in and memory read-out. There is no routine way to easily imagine how these 
activities could be arranged to provide the sophistication of the brain. To this end, we have invented a computational scheme that incorporates a singular compound access operation, and learning happens via Big Data amassment and cluster access. This scheme can be implemented with a new structure of associative memory, which appears in the Holographic Universe. The discovery of cells in the brain that constitute a positioning system, like GPS (Nobel Prize in Medicine, 2014) implies that the organization of the brain might indeed share the exclusive outside hardware resources by Cloud Computing. The suggested associative memory realizes continuous holographic recordings of incoming data in moving 2D layers. This way, we can get a universal operation of the two stage access to associative memory: stage one combines actions of "Write down an applied new datum - with prelude "Marking the old data matching the applied pattern"; stage two performs "Read out" of the just recorded datum and the "Marked" items from a stream in a reverse order. The Cyber-physical stream selection of a majority element [5] modifies the customary practice of resolution multiple responses to the suggested cluster intelligence access. The developed construction challenges the primary illusion in the design of the brain as an apparition of separate short and long-term memories. Distortions of the suggested universal operation of access to this associative memory display typical initial symptoms of Alzheimer's dementia simultaneously: loss of recent memories while soundly recalling early events. A variety of testable predictions can be considered. The suggested associative memory operations are performed in a stream fashion with spreading 2D sections where different pieces present the cortical map at the glial interface between the outside memory and the internal neuronal circuitry. Restricted to 2D sections, brain can effectively manage only 3D objects [6]. Functioning of the brain is a continuous series of transformations of the given cortical map; they are inherited ab ovo through Cloud Computing. Subsequently, human life constitutes in total around $10^{20}$ of these transformations.

\section{References}

1. Berkovich E (2007) Method of and system for searching a data dictionary with fault tolerant indexing US Patent number: 7168025 Date of Patent January 23, 2007.

2. Berkovich S, Liao D (2012) On clusterization of "big data" sreams. COM.Geo12 Proc. of the 3rd International Conference for Geospatial Research and Applications, ACM, New York, Washington, DC, USA, ISBN: 978-1-4503-1113-7.

3. Berkovich S (2014) Organization of the brain in Light of the Big Data Philosophy Fifth International Conference on Computing for Geospatial Research and Application pp. 91-92.

4. Berkovich S (1993) On the information processing capabilities of the brain: shifting the paradigm. Nanobiology 2: 99-107.

5. Alhudhaif A, Yammahi M, Yan T, Berkovich S (2015) A CyberPhysical Stream Algorithm for Intelligent Software Defined Storage. International Journal of Computer Applications (0975-8887) 109(5): 21-25.

6. Berkovich S (2010) Holographic model of human memory and tridimensionality of the space of perception.

\section{Your next submission with Juniper Publishers will reach you the below assets}

- Quality Editorial service

- Swift Peer Review

- Reprints availability

- E-prints Service

- Manuscript Podcast for convenient understanding

- Global attainment for your research

- Manuscript accessibility in different formats

( Pdf, E-pub, Full Text, Audio)

- Unceasing customer service

Track the below URL for one-step submission https://juniperpublishers.com/online-submission.php 